\title{
Use of Cardiotocogram (CTG) as an Admission Test as a Predictor of Foetal Outcome in Labour in Low Risk Group
}

\author{
Sowmyashree Thimmappa ${ }^{1}$, Sujatha N. Datti ${ }^{2}$ \\ ${ }^{1}$ Resident, Department of Obstetrics and Gynaecology, MVJ Medical College and Hospital, Hoskote, Karnataka, India. \\ ${ }^{2}$ Professor, Department of Obstetrics and Gynaecology, MVJ Medical College and Hospital, Hoskote, Karnataka, India.
}

\section{ABSTRACT}

\section{BACKGROUND}

Intrapartum foetal morbidity and mortality is not uncommon in a low risk population. Any foetus has the potential risk of intrapartum hypoxia which may lead to birth injury. CTG as admission test can be used in low risk pregnant women as an alternative to continuous electronic foetal monitoring. We wanted to evaluate the role of Cardiotocogram (CTG) as admission test in intrapartum low risk pregnant women and to predict foetus at risk of adverse outcome.

\section{METHODS}

This is a prospective observational study which included 200 low risk pregnant women with $>37$ weeks of gestation in labour. All 200 pregnant women were subjected to admission test (AT) using Sonicaid foetal monitor for 20 minutes. The trace thus obtained was classified as normal, suspicious and pathological AT as per NICE guidelines. ${ }^{1}$ Admission test results were compared with various labour outcome variables i.e., incidence of foetal distress, mode of delivery, neonatal outcome in relation to AT result. Statistical analysis is done using chi square test and $p$ value of $<0.01$ is taken as statistically significant.

\section{RESULTS}

Out of 200 patients, 164 (82\%), 20 (10\%) and 16 (8\%) had normal, suspicious and pathological admission test result respectively. The incidence of foetal distress (100\% Vs $7.92 \%)$, caesarean section rate (100\% Vs 7.3\%), low Apgar score at 5' (50\% Vs $4.87 \%$ ), NICU admission ( $50 \%$ Vs $4.87 \%$ ) was higher in pathological AT group than in normal AT group. There was one neonatal death in pathological admission test group. Sensitivity, Specificity, PPV, NPV and over all diagnostic accuracy was 54.45\%, $92 \%, 69 \%, 93 \%$ and $83 \%$ respectively.

\section{CONCLUSIONS}

Admission test in this study had low sensitivity but high specificity. High specificity in predicting foetus at risk of foetal distress, supports its use as admission test in low risk pregnant women. Early intervention in pathological admission test group reduced the incidence of neonatal morbidity inspite of low sensitivity in detecting distressed foetus. Specificity of $92 \%$ and NPV of $93 \%$ supports its role as admission test in low risk pregnant women.

\section{KEY WORDS}

CTG, Foetal Distress, Low Risk Pregnancy, Apgar Score, Perinatal Outcome, EFM
Corresponding Author: Dr. Sowmyashree Thimmappa, D. No. 25, $6^{\text {th }}$ Cross, $5^{\text {th }}$ Main, M-Block, Kuvempunagar Nagar, Mysuru-570023, Karnataka, India. E-mail:sownshree@gmail.com

DOI: $10.14260 /$ jemds/2019/632

Financial or Other Competing Interests: None.

How to Cite This Article:

Thimmappa S, Datti SN. Use of cardiotocogram (CTG) as an admission test as a predictor of foetal outcome in labour in low risk group. J. Evolution Med. Dent. Sci. 2019;8(38):2911-2914, $10.14260 /$ jemds/2019/632

Submission 07-05-2019, Peer Review 05-09-2019, Acceptance 11-05-2019, Published 23-09-2019. 


\section{BACKGROUND}

Foetal monitoring is essential during labour to ensure delivery of healthy foetus. Although widely considered the best method of delivery for the mother and the baby, a vaginal birth is not bereft of risks. Although the introduction of intrapartum foetal surveillance has not been able to make this journey any easier, it has certainly helped in making it much safer than it has ever been. Routine electronic foetal heart rate monitoring in labour has become an established obstetric practice in western world. In labour wards with few monitors, selection of patients for continuous monitoring or intermittent auscultation is necessary. Risk assessment based on antepartum factors is not accurate as predictors of foetal outcome, as foetal heart rate changes and foetal acidosis might occur in low risk group. Continuous electronic foetal monitoring is not accepted in low risk women. Admission CTG can be used as an objective method to optimize the outcome in low risk pregnant women in labour.

Foetal morbidity and mortality is also observed in low risk population in the intrapartum period. Any foetus has the potential risk of intrapartum hypoxia which may lead to birth injury. If for some reason continuous monitoring cannot be applied, alternative ways of using monitors might be of interest, such an alternative is the admission CTG. Admission test is recording of foetal heart rate and uterine contraction in labour for a period of 20 minutes.

This study evaluates the role of CTG as admission test (AT) in intrapartum patient to predict foetus at risk for adverse outcome in low risk cases.

\section{METHODS}

The prospective observational study population included 200 low risk pregnant women in labour admitted at MVJ Medical College and Research Hospital, Hoskote. Singleton pregnancies with $>37$ weeks of gestation with cephalic presentation with intact membranes in 1st stage of labour were included in the study. Patients were first given a description of the procedure they have to undergo after a preliminary history taking, thorough general examination \& obstetric examination. Informed consent was taken. Later patients were subjected to admission test using sonicaid foetal monitor at speed of 3 $\mathrm{cm} / \mathrm{min}$ for 20 minutes after ensuring maternal hydration and food intake. The trace thus obtained was classified as Normal, Suspicious, and Pathological according to National Institute of Clinical Excellence (NICE) guidelines (2007). ${ }^{1}$ In patients with suspicious admission test, a 20 minutes extended strip was taken after the following actions: Repositioning of patients, discontinuation of uterine stimulants, administration of oxygen to the mother, correction of maternal dehydration. The trace obtained is again classified as normal, suspicious or pathological.

Patients with normal admission test were followed by intermittent auscultation for 1 minute every 30 minutes in first stage and every 5 minutes once in second stage of labour. Patients with persistently suspicious admission test were monitored by continuous electronic monitoring. In patients with pathological admission test, appropriate intervention was taken immediately. Admission test was repeated at 6 hrs., if labour progressed for $>6 \mathrm{hrs}$, in normal admission test group and suspicious admission test group. Foetal distress was considered to be present when pathological FHR changes were seen and led to LSCS or instrumental vaginal delivery on that indication or Apgar score of less than 7 at 5 minutes. Labour outcome was assessed with respect to incidence of foetal distress during labour, operative deliveries, Apgar score at 1 minute and 5 minutes \& neonatal intensive care admissions.

The data collected is analysed statistically by computing the sample statistic. The statistical analysis was done using statistical test -chi square test. The results were considered significant if $\mathrm{p}$ value $<0.01$.

\section{RESULTS}

The maximum number of patients belonged to 20-25 years age group. Out of the 200 women who underwent admission test, $82 \%$ had normal admission test, $10 \%$ showed suspicious admission test \& $8 \%$ had pathological admission test.

\begin{tabular}{|c|c|}
\hline Maternal Age in Years & No. of Women, $\mathbf{n = 2 0 0}$ \\
\hline$<20$ & 18 \\
\hline $20-25$ & 112 \\
\hline $26-30$ & 70 \\
\hline \multicolumn{2}{|c|}{ Table 1. Maternal Age Distribution } \\
\hline Mean \pm SD: 22.49 \pm 3.13 \\
\hline
\end{tabular}

$7.92 \%, 45 \%$ and $100 \%$ of the women in normal admission test group, suspicious admission test group, pathological admission test group developed foetal distress respectively. A total of 38 patients (19\%) developed foetal distress in the present study. The incidence of foetal distress increases as the trace progress towards pathological trace $\chi^{2}=90.100$ and the $p$ value $<0.001$, which suggests that the values obtained in the study are highly significant. In normal admission test group $84.2 \%$ had vaginal delivery, $8.5 \%$ had instrumental delivery and $7.3 \%$ had LSCS. In suspicious admission test group 35\% had vaginal delivery, $20 \%$ had instrumental delivery and $45 \%$ underwent LSCS. In pathological admission test group 100\% patients underwent LSCS. p value $<0.001$, suggests that the values obtained in the study are highly significant.

\begin{tabular}{|c|c|c|c|c|}
\hline Sl. No. & & $\begin{array}{c}\text { Normal } \\
\text { AT n (\%) }\end{array}$ & $\begin{array}{c}\text { Suspicious } \\
\text { AT n (\%) }\end{array}$ & \begin{tabular}{|c} 
Pathological \\
AT n (\%) \\
\end{tabular} \\
\hline 1. & No of women & $164(82)$ & $20(10)$ & $16(8)$ \\
\hline 2. & Foetal distress & $13(7.92)$ & $9(45)$ & $16(100)$ \\
\hline 3. & Mode of delivery & & & \\
\hline a) & Vaginal delivery & $138(84.2)$ & $7(35)$ & - \\
\hline b) & Instrumental delivery & & & \\
\hline i. & With foetal distress & $6(3.65)$ & $3(15)$ & - \\
\hline ii. & Without foetal distress & $8(4.87)$ & $1(5)$ & - \\
\hline c) & LSCS & & & \\
\hline i. & With foetal distress & $7(4.26)$ & $6(30)$ & $16(100)$ \\
\hline ii. & Without foetal distress & $5(3.04)$ & $8(15)$ & - \\
\hline 4. & Neonatal outcome & & & \\
\hline a) & $\begin{array}{c}\text { Apgar score } \\
>7-5^{\prime} \\
<7-5^{\prime}\end{array}$ & $\begin{array}{c}156(95.12) \\
8(4.87)\end{array}$ & $\begin{array}{c}15(75) \\
5(25)\end{array}$ & $\begin{array}{l}8(50) \\
8(50)\end{array}$ \\
\hline b) & NICU admission & $8(4.87)$ & $5(25)$ & $8(50)$ \\
\hline \multicolumn{5}{|c|}{ Table 2. Maternal and Foetal Outcome } \\
\hline
\end{tabular}

Only in a minority of cases i.e. $4.87 \%$, in normal admission test group, the admission test did not predict poor perinatal outcome (APGAR<7 at $5^{\prime}$ ). In suspicious group $25 \%$ of the neonates had APGAR <7 at 5'. Among the patients with pathological trace false positive rate was $50 \%$. $8(4.87 \%)$ 
Neonates out of 164 patients in normal admission test group $5(25 \%)$ neonates out of 20 patients in the suspicious admission test group and $8(50 \%)$ neonates of patients with pathological admission test group had NICU admission. $\chi^{2}=$ 36.60 and $\mathrm{P}<0.001$ suggests that the value obtained in the study are statistically significant.

\begin{tabular}{|c|c|c|c|c|c|c|}
\hline $\begin{array}{c}\text { Sl. } \\
\text { No. }\end{array}$ & $\begin{array}{c}\text { Mode of } \\
\text { Delivery }\end{array}$ & $\begin{array}{c}\text { Admission } \\
\text { test To } \\
\text { Delivery } \\
\text { Interval }\end{array}$ & $\begin{array}{c}\text { Birth } \\
\text { Weight } \\
\text { in Kg }\end{array}$ & $\begin{array}{c}\text { Colour } \\
\text { of } \\
\text { Liquor }\end{array}$ & $\begin{array}{c}\text { Apgar } \\
\text { Score } \\
\mathbf{1}^{\prime}-\mathbf{5}^{\prime}\end{array}$ & $\begin{array}{c}\text { NICU } \\
\text { Admission }\end{array}$ \\
\hline 1 & LSCS & $6 \mathrm{hrs}$. & 3.5 & Clear & $8-9$ & \\
\hline 2 & LSCS & $5 \mathrm{hrs}$. & 2.7 & Thick & $7-8$ & \\
\hline 3 & Outlet Forceps & $3 \mathrm{hrs}$. & 2.6 & Thick & $5-6$ & 6 days MAS \\
\hline 4 & LSCS & $8 \mathrm{hrs}$ & 3 & Clear & $8-9$ & \\
\hline 5 & LSCS & 2 hrs. 15 min & 2.9 & Thin & $8-9$ & \\
\hline 6 & Outlet forceps & 2 hrs. 30 min & 2.8 & Thin & $7-8$ & \\
\hline 7 & Outlet forceps & 3 hrs. & 2.8 & Thin & $7-8$ & \\
\hline 8 & LSCS & 3 hrs. & 2.6 & Thick & $5-6$ & 5 days \\
\hline 9 & Outlet forceps & 4 hrs. & 3.3 & Thin & $5-6$ & 2 days \\
\hline 10 & Outlet forceps & 3 hrs 10 min & 2.8 & Thick & $5-6$ & 2 days \\
\hline 11 & LSCS & 7 hrs. & 3.2 & Clear & $5-6$ & 2 days \\
\hline 12 & LSCS & 2 hrs & 3 & Thick & $5-6$ & 4 days \\
\hline 13 & Outlet forceps & 2 hrs. 30 min & 2.9 & Thick & $8-9$ & \\
\hline \multicolumn{7}{|c|}{ Table 3. Outcome of 13 Patients with Normal Trace who } \\
\hline \multicolumn{7}{|c|}{ Developed Foetal Distress during Labour } \\
\hline
\end{tabular}

Admission test was false negative in predicting foetal distress during labour in 13 cases, but only 6 newborns had poor perinatal outcome.

\begin{tabular}{|c|c|c|c|c|c|c|}
\hline $\begin{array}{c}\text { SI. } \\
\text { No. }\end{array}$ & $\begin{array}{c}\text { Mode of } \\
\text { Delivery }\end{array}$ & $\begin{array}{c}\text { Admission } \\
\text { Test to } \\
\text { Delivery } \\
\text { Interval }\end{array}$ & $\begin{array}{c}\text { Colour } \\
\text { of } \\
\text { Liquor }\end{array}$ & $\begin{array}{c}\text { Birth } \\
\text { Weight } \\
\text { in kg }\end{array}$ & $\begin{array}{c}\text { Apgar } \\
\text { Score } \\
\mathbf{1}^{\prime}-5\end{array}$ & $\begin{array}{c}\text { NICU } \\
\text { Admission }\end{array}$ \\
\hline 1 & LSCS & 6 hrs. & Clear & 3.1 & $8-9$ & \\
\hline 2 & LSCS & 2 hrs. 30 min & Thick & 2.8 & $5-6$ & 3 days \\
\hline 3 & LSCS & 3 hrs. & Thick & 2.7 & $5-6$ & 5 days \\
\hline 4 & LSCS & 2 hrs. & Thick & 2.3 & $5-6$ & 4 days \\
\hline 5 & Outlet forceps & 2 hrs. 30 min & Thin & 3.3 & $5-6$ & 1 day \\
\hline 6 & LSCS & 4 hrs. 20 min & Thick & 3.4 & $7-6$ & \\
\hline 7 & $\begin{array}{c}\text { Outlet } \\
\text { forceps }\end{array}$ & 5 hrs. & Clear & 3.1 & $8-9$ & \\
\hline 8 & Outlet forceps & 3 hrs. 20 min & Clear & 3 & $8-9$ & \\
\hline 9 & LSCS & 2 hrs. & Clear & 3.5 & $8-9$ & \\
\hline \multicolumn{7}{|c|}{ Table 4. Patients with Foetal Distress in Suspicious Admission Test } \\
\hline
\end{tabular}

In patients with suspicious trace and clear liquor, the perinatal outcome was good.

\begin{tabular}{|c|c|c|c|c|c|c|}
\hline $\begin{array}{r}\text { Sl. } \\
\text { No. }\end{array}$ & $\begin{array}{l}\text { Mode of } \\
\text { Delivery }\end{array}$ & \begin{tabular}{|c|} 
Admission \\
Test to \\
Delivery \\
Interval \\
\end{tabular} & $\begin{array}{c}\text { Colour } \\
\text { of } \\
\text { Liquor }\end{array}$ & $\begin{array}{c}\text { Birth } \\
\text { Weight } \\
\text { in Kgs }\end{array}$ & $\begin{array}{c}\text { Apgar } \\
\text { Score } \\
1^{\prime}-5^{\prime}\end{array}$ & $\begin{array}{c}\text { NICU } \\
\text { Admission }\end{array}$ \\
\hline 1 & LSCS & $40 \mathrm{Min}$ & Thick & 2.6 & $4-5$ & 15 days MAS \\
\hline 2 & LSCS & 45 Min & Thick & 2.7 & $8-9$ & \\
\hline 3 & LSCS & $1 \mathrm{Hr}$ & Thick & 2.7 & $5-6$ & \\
\hline 4 & LSCS & 40 Min & Thick & 2.7 & $8-9$ & \\
\hline 5 & LSCS & 40 Min & Thick & 2.7 & $2-4$ & 10 days, MAS \\
\hline 6 & LSCS & 45 Min & Thick & 2.9 & $5-6$ & 3 days \\
\hline 7 & LSCS & 50 Min & Thick & 3.2 & $7-8$ & \\
\hline 8 & LSCS & 30 Min & Thick & 2.9 & $2-4$ & $\begin{array}{c}\text { Baby died on } \\
\text { second PND due } \\
\text { to birth asphyxia }\end{array}$ \\
\hline 9 & LSCS & $40 \mathrm{~min}$ & Thin & 2.8 & $7-9$ & \\
\hline 10 & LSCS & $45 \mathrm{~min}$ & Thin & 2.8 & $7-8$ & \\
\hline 11 & LSCS & 40 Min & Thick & 2.7 & $4-5$ & 14 days, MAS \\
\hline 12 & LSCS & 50 Min & Thick & 3.8 & $5-6$ & 4 days \\
\hline 13 & LSCS & 40 Min & Thin & 3 & $8-9$ & \\
\hline 14 & LSCS & $55 \mathrm{~min}$ & Thin & 3.1 & $8-9$ & \\
\hline 15 & LSCS & 45 Min & thick & 3.2 & $4-6$ & 2 days \\
\hline 16 & LSCS & 40 Min & thick & 3.2 & $5-6$ & 1 day \\
\hline
\end{tabular}

In patients with pathological trace and thick meconium stained liquor perinatal outcome was poor which included one neonatal death. With pathological trace false positive rate to predict perinatal outcome was $50 \%$; this could probably be the result of an early intervention and, hence improving the perinatal outcome.

\begin{tabular}{|c|c|}
\hline Sensitivity & $54.45 \%$ \\
\hline Specificity & $93 \%$ \\
\hline Positive predictive value & $69 \%$ \\
\hline Negative predictive value & $92 \%$ \\
\hline Diagnostic accuracy & $88 \%$ \\
\hline Table 6. Diagnostic Utility of Admission Test (Outcome/
\end{tabular}

Table 6. Diagnostic Utility of Admission Test (Outcome/ Foetal Distress)

The above table depicts the diagnostic utility of cardiotocography as admission test in labour. As seen in the above table, specificity is high. However, the sensitivity is low.

\section{Statistical Analysis}

Statistical analysis of the data obtained from the study population was done using Chi-square test $\left(\chi^{2}\right)$ with the use of computer software SPSS version 10. Statistical significance was calculated between groups with reactive, equivocal and ominous AT. The results obtained were considered statistically significant if $\mathrm{p}$ value $<0.01$.

\section{DISCUSSION}

British guidelines published in $2001^{2}$ do not recommend the labour admission test in low risk women, while Swedish guidelines published the same year ${ }^{3}$ recommend the test in all women. The British recommendations were based upon three studies, ${ }^{4,5,6}$ and the Swedish upon seven studies. $4,7-12$

Over the years it has been recognized that foetal morbidity and mortality occurs as a consequence of labour even in patients categorized as low risk based on various risk classifications. Indeed, about half of admission to NICU derives from so called low risk pregnancies.

The study population in this study included 200 low risk pregnant women admitted to labour ward of MVJMC AND RH. The correlation of admission test with $5^{\prime}$ Apgar score was good. Reactive trace was followed by $96.34 \%$ of babies with Apgar score $>7$ at 5 minutes. Thus, only in minority of cases $(3.65 \%)$ admission test with normal trace did not predict poor perinatal outcome.

An abnormal admission test was associated with $52.7 \%$ of babies with Apgar score of $<7$ at 5 minutes. Thus, ominous admission test was false positive in predicting perinatal outcome in $47.22 \%$. From an analysis of this study, it would be safe to conclude that normal admission test could be followed by intermittent auscultation every 30 minutes in $1^{\text {st }}$ stage and every 5 minutes in the $2^{\text {nd }}$ stage. An ominous admission test should be managed appropriately without delay.

The incidence of foetal distress in the reactive admission test group, in the study by Ingemarssan et al ${ }^{4}$ and Aparna et $\mathrm{al}^{13}$ are $3.6 \%$ and $1.3 \%$ respectively. In the present study incidence of foetal distress in normal admission test group is $7.92 \%$ which is comparable with the study by Kushtagi $\mathrm{P}$ et al. ${ }^{14}$ Thus in $7.92 \%$ patients the admission test did not predict foetal distress in this study. Thus, the admission test was false negative in predicting foetal distress in labour in $7.92 \%$ patients. In the suspicious admission test group, the incidence of foetal distress in the present study is $45 \%$ which is comparable with studies by Kushtagi $\mathrm{P}$ et al. In the present study the incidence of foetal distress in pathological admission test is $100 \%$ which is comparable with the studies by Aparna 
Hedge et al ${ }^{13}$ and Kushtagi $\mathrm{P}$ et al. ${ }^{14}$ Thus pathological admission test was false positive in predicting poor perinatal outcome in $50 \%$ of the patients. As we can see in the above table that in all the studies the incidence of foetal distress is increasing as the trace progress from suspicious to pathological trace. In the present study also, we see that the incidence of foetal distress is increasing as the trace is progressing towards pathological trace. Thus, admission test can detect foetal distress already present at admission and unnecessary delay in intervention can be avoided in such a case.

The correlation of admission test with 5' Apgar score was good. Reactive trace was followed by $96.34 \%$ of babies with Apgar score $>7$ at 5 minutes. Thus, only in minority of cases (3.65\%) admission test with normal trace did not predict poor perinatal outcome.

An abnormal admission test was associated with $52.7 \%$ of babies with Apgar score of $<7$ at 5 minutes. Thus, ominous admission test was false positive in predicting perinatal outcome in $47.22 \%$. From an analysis of this study, it would be safe to conclude that normal admission test could be followed by intermittent auscultation every 30 minutes in $1^{\text {st }}$ stage and every 15 minutes in the $2^{\text {nd }}$ stage. An ominous admission test should be managed appropriately without delay.

In the present study the sensitivity is $54.45 \%$ which is comparable with that of Kushtagi $\mathrm{P}$, et al ${ }^{15}$ study. In the studies by Ingemarsson et $\mathrm{al}^{4}$ and Kamal Buckshee et $\mathrm{al}^{15}$ the sensitivity is $23.5 \%$ and $21.43 \%$ respectively. Thus, admission test as a low sensitivity and high specificity. Cardiotocography as admission test showed sensitivity of $53.8 \%$ and high specificity of $92 \%$. Although the sensitivity is low, its high specificity low cost and the ease of doing, support its role as admission test.

\section{CONCLUSIONS}

This study evaluates the use of CTG as a means of admission test for triage of cases requiring continuous monitoring in low risk obstetric patients. It tries to study the ability of the test to identify or predict the foetal distress at the time of admission to labour room. Cardiotocography as admission test showed sensitivity of $54.45 \%$ and high specificity of $92 \%$ in the present study. It can detect foetal distress already present on admission. It is a simple test, easy to perform and is a good alternative to labelling low risk patients in labour either to intermittent auscultation or continuous monitoring in poor resource settings. The reactive admission CTG is associated with low risk for foetal distress as measured by Apgar score and pathological CTG is associated with high risk for foetal distress. Early intervention in pathological admission test group reduced the incidence of neonatal morbidity inspite of low sensitivity in detecting distressed foetus. Specificity of $92 \%$ and NPV of $93 \%$ supports its role as admission test in low risk pregnant women. From an analysis of this study, it would be safe to conclude that an ominous admission test should be managed appropriately without delay and obstetrician should be more vigilant in patients with suspicious as well as normal admission test by doing continuous or intermittent monitoring, for timely intervention.

\section{REFERENCES}

[1] National Institute for Clinical Excellence (NICE). Intrapartum care: Care of healthy women and their babies during childbirth. London: RCOG Press 2007.

[2] Royal College of Obstetricians and Gynaecologists. The use of electronic foetal monitoring. London: RCOG Press 2001.

[3] Nordström L, Waldenström U. Handläggning av normal födsel (Management of normal labour). Stockholm: Socialstyrelsen 2001.

[4] Ingemarsson I, Arulkumaran S, Ingemarsson E, et al. Admission test: a screening test for foetal distress in labour. Obstet Gynecol 1986;68(6):800-6.

[5] Umstad MP. The predictive value of abnormal foetal heart rate patterns in early labour. Aust N Z J Obstet Gynaecol 1993;33(2):145-9.

[6] Kulkarni AA, Shrotri AN. Admission test: a predictive test for foetal distress in high risk labour. J Obstet Gynaecol Res 1998;24(4):255-9.

[7] Phelan JP. Labor admission test. Clin Perinatol 1994;21(4):879-85.

[8] Phelan JP, Ahn MO. Perinatal observations in forty-eight neurologically impaired term infants. Am J Obstet Gynecol 1994;171(2):424-31.

[9] Phelan JP. The nonstress test: a review of 3,000 tests. Am J Obstet Gynecol 1981;139(1):7-10.

[10] Krebs HB, Petres RE, Dunn LJ, et al. Intrapartum foetal heart rate monitoring. VI. Prognostic significance of accelerations. Am J Obstet Gynecol 1982;142(3):297-305.

[11] Ducey J, Guzman E, Schulman H, et al. Value of a screening foetal heart rate tracing in the latent phase of labor. J Reprod Med 1990;35(9):899-900.

[12] Sarno AP Jr, Phelan JP, Ahn MO. Relationship of early intrapartum foetal heart rate patterns to subsequent patterns and foetal outcome. J Reprod Med 1990;35(3):239-42.

[13] Aparna H, Shailesha K, Sushma S, et al. Admission test: screening test for prediction of foetal outcome in labour. J of Obstest \& Gynaec of India 2001;51(2):40-3.

[14] Kushtagi P, Naragoni S. Labour admission test - an effective risk screening tool. J Indian Med Assoc 2002;100(4):234-6.

[15] Buckshee K, Deka D, Padmaja V. Admission test as predictor of foetal outcome. J of Obstet and Gynec of India 1999;49(2):36-7. 